\title{
AMS DATING OF POLLEN CONCENTRATES-A METHODOLOGICAL STUDY OF LATE QUATERNARY SEDIMENTS FROM SOUTH WESTLAND, NEW ZEALAND
}

\author{
Marcus J Vandergoes \\ Climate Change Institute, University of Maine, Orono, Maine 04469, USA. \\ Corresponding author. Email: vandergoes@maine.edu. \\ Christine A Prior \\ Rafter Radiocarbon Laboratory, Institute of Geological and Nuclear Sciences Ltd, Lower Hutt, New Zealand.
}

\begin{abstract}
A simple method for preparing pollen concentrates for ${ }^{14} \mathrm{C}$ AMS dating is applied to organic and inorganic deposits from a peat bog in south Westland, New Zealand, from which preliminary AMS dating indicated age inversions and severe younger carbon contamination problems. The AMS ages of the pollen concentrates provided consistently older age estimates for each sample than ages derived from their respective organic residue or combined pollen and organic residue fractions. It is likely that the younger age estimates of the organic residue fractions result from the incorporation of younger plant material into the sample and possible contamination from younger humic acids percolating through the site.
\end{abstract}

\section{INTRODUCTION}

The advantages of radiocarbon dating concentrated pollen by accelerator mass spectrometry (AMS) from late Pleistocene and Holocene deposits have long been recognized (Brown et al. 1989, 1992; Regnell 1992) and the ability to obtain reliable ${ }^{14} \mathrm{C}$ ages from pollen is well established (Mensing and Southon 1999). Studies have shown that AMS dating of pollen concentrates can eliminate many of the problems inherent with conventional ${ }^{14} \mathrm{C}$ dating of lake, marine, and peat deposits (Long et al. 1992; Richardson and Hall 1994; Regnell and Everitt 1996). The application of AMS dating pollen concentrates to pollen analysis is of great importance, particularly where bulk samples are contaminated by either younger or older carbon. In these instances, AMS ages from pollen concentrates can provide more reliable chronologies and potentially reduce dating errors associated with short-lived paleoclimate events, including regional deglaciations, cooling, and tree species migration (Brown et al. 1992).

In the last decade, many techniques have been developed and improved to prepare relatively pure pollen concentrate samples for AMS dating. To date, pollen extraction procedures combine treatments including chemical digestion of organic matter using strong acids such as $\mathrm{H}_{2} \mathrm{SO}_{4}$ and fine sieving (Regnell 1992), microbiological degradation (Richardson and Hall 1994), centrifugation (Regnell and Everitt 1996), and manual separation with a micromanipulator (Long et al. 1992) or mouth pipette (Mensing and Southon 1999). Although clear improvements have resulted from some of these procedures, many are still not able to completely remove contaminants (Regnell 1992; Richardson and Hall 1994), or are limited to only concentrating large pollen grains from relatively large volume samples (Long et al. 1992; Mensing and Southon 1999).

Whereas these techniques have been generally successful when concentrating pollen from Holocene deposits or sediments containing large pollen grains, they become less efficient when attempting to concentrate pollen from:

- Sediments where pollen grain sizes are predominantly small $(<50 \mu \mathrm{m})$, such as those associated with the Last Glacial Maximum (LGM) in New Zealand.

- Sediments where the volume of sediment available for dating a palynological event is limited.

A simple technique for preparing pollen concentrates for AMS dating using heavy liquid separation (Prior and Chester 2001) has previously been used to derive datable material from small volumes of 
Holocene sediment. This technique is considered to provide more accurate age estimates of greater precision than conventional ages from bulk sediment, particularly for dating vegetation changes interpreted from pollen analysis (Prior and Chester 2001; Horrocks et al. 2002). This paper tests the applicability of the method by attempting to produce more reliable ages from late Quaternary depositional environments in Westland, New Zealand, where severe ${ }^{14} \mathrm{C}$ contamination problems have been reported previously (Grant-Taylor and Rafter 1971; Moar and Suggate 1979; Hammond et al. 1991). All ${ }^{14} \mathrm{C}$ ages are reported in ${ }^{14} \mathrm{C}$ years before present (yr BP), although where stated, calibrated years have been determined using INTCAL98 (Stuiver et al. 1998).

\section{SITE INFORMATION AND ${ }^{14} \mathrm{C}$ DATING PROBLEMS OF SOUTH WESTLAND, NEW ZEALAND}

A 5-cm-diameter core was taken from a peat deposit (Okarito Pakihi) $70 \mathrm{~m}$ above sea level, near Okarito Lagoon in south Westland, New Zealand ( $43^{\circ} 14^{\prime} 50^{\prime \prime} \mathrm{S}$; $170^{\circ} 12^{\prime} 25^{\prime \prime} \mathrm{E}$; Figure 1), using a modified Russian D-section corer. Palynological and sedimentological analysis indicates that the site was formed as a lake impounded behind glacial terminal moraines that predate the LGM, but are close to the limits of LGM ice advances. The site became a peat bog after about $10 \mathrm{ka}$ BP and provides a record of sediment and vegetation change that predates the LGM. The catchment around the site consists of non-carbonate lithologies (Warren 1967) and there are no indications of a "hardwater effect" in any previous ${ }^{14} \mathrm{C}$ dating reported for this region.

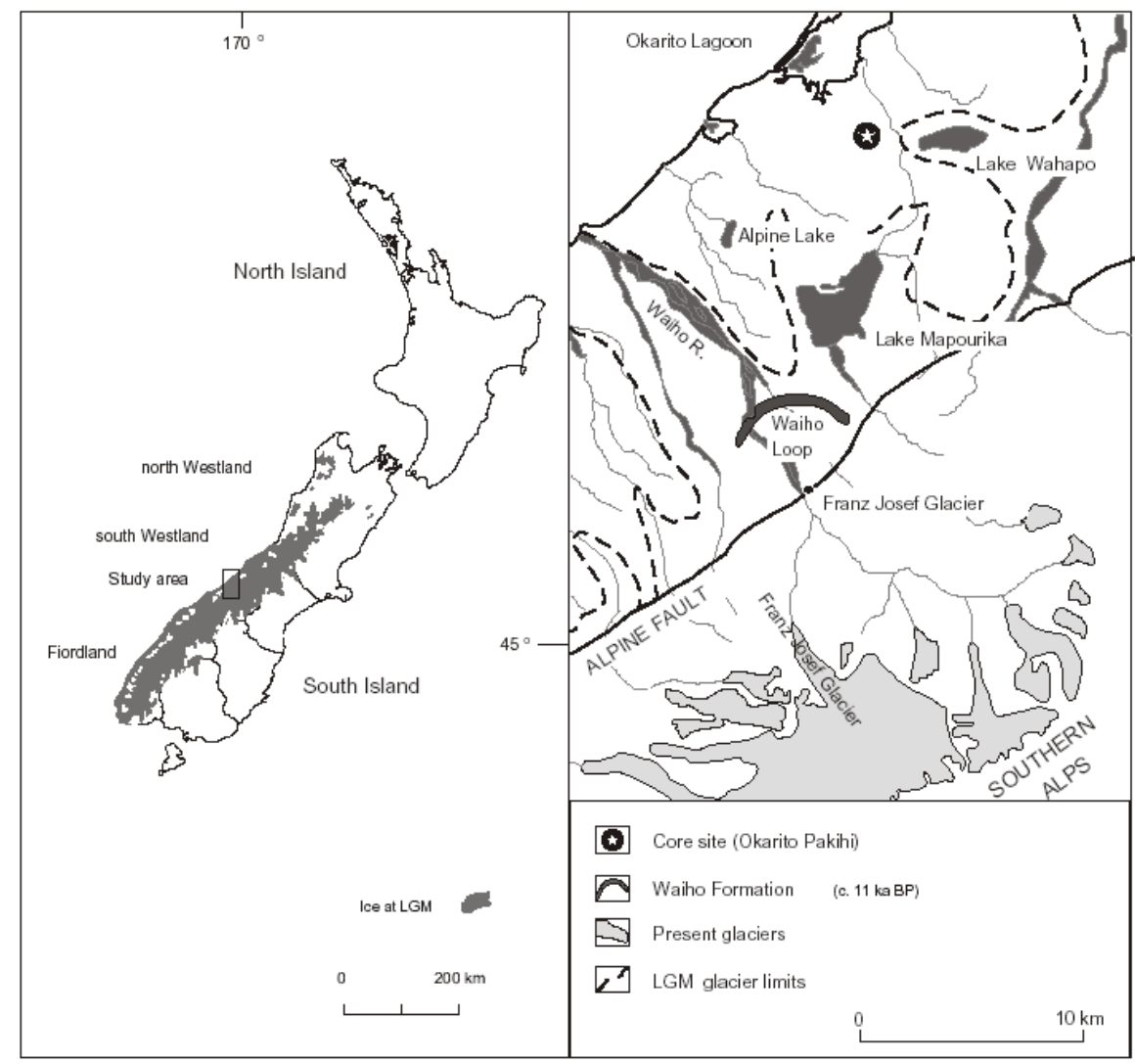

Figure 1 Geologic and geomorphic map of the study area showing location of the study site at Okarito Pakihi, along with present and historic glacier extents (modified from Warren 1967). 
An important feature in the development and maintenance of south Westland's landscape is the regional climate - in particular, rainfall. Precipitation is high, averaging $5000 \mathrm{~mm} \mathrm{yr}^{-1}$ at low altitudes in south Westland, and rises in the adjacent Southern Alps to as much as $15,000 \mathrm{~mm} \mathrm{yr}^{-1}$ (Chinn and Whitehouse 1980). The steep precipitation gradient is characteristic of New Zealand's Southern Alps, which have a strong orographic influence on the prevailing westerly and south westerly air streams. Consequently, dry periods are rare and lowland mean annual temperatures are around $15.3^{\circ} \mathrm{C}$ in summer (January) and $6.7{ }^{\circ} \mathrm{C}$ in winter (July) (Garnier 1958; New Zealand Meteorological Service 1983).

Preliminary AMS ages of bulk sediment and wood macrofossils from Okarito Pakihi provide age estimates of 10,267 $\pm 70 \mathrm{BP}, 9692 \pm 65 \mathrm{BP}$, and $9758 \pm 70$ BP between $281-283 \mathrm{~cm}$, and date the beginning of organic sedimentation and dominance of a tall Podocarp forest occurring at the onset of the Holocene (Table 1, Figure 2). Toward the base of the core, organic silts at $553-554 \mathrm{~cm}$ and $599-600 \mathrm{~cm}$ provide ages of $31,080 \pm 490 \mathrm{BP}$ and $35,630 \pm 430 \mathrm{BP}$, respectively, and constrain the lowermost peak in all tree pollen (Figure 2). However, bulk AMS ages from the center of the core indicate an age inversion (Figure 2), where samples consisting of inorganic silty-sand bracket the peaks in herb pollen and yield AMS ages of 12,069 $\pm 60 \mathrm{BP}(349-350 \mathrm{~cm})$ and 11,228 $\pm 90 \mathrm{BP}$ (390-391 cm), respectively.

Of the preliminary ages, all those that are older than about $10 \mathrm{ka} \mathrm{BP}$ are considered to be too young. The herb-dominated pollen assemblage, dated here by inverted ages of 12,069 $\pm 60 \mathrm{BP}$ and 11,228 $\pm 90 \mathrm{BP}$, is generally interpreted to represent flora associated with the LGM between about 22-16 ka BP (Moar and Suggate 1996). Below this, the lowermost peak in tall tree pollen, dated here between $31,080 \pm 490 \mathrm{BP}$ and $35,630 \pm 430 \mathrm{BP}$, is likely to represent flora older than $70 \mathrm{ka} \mathrm{BP}$ associated with Marine Oxygen Isotope Stage 5a.

The age inversions between $349-400 \mathrm{~cm}$ provide evidence that some of the AMS-dated samples were contaminated by younger or older carbon. An older ${ }^{14} \mathrm{C}$ age may result from the inwash of older inorganic carbon residues into the site or the incorporation of dissolved carbonates into the tissue of aquatic organisms or the sediment (hardwater effect). A younger ${ }^{14} \mathrm{C}$ age can result from root penetration through the profile, the percolation of humic acid through the deposit, or the downward movement of younger sediments through bioturbation from burrowing organisms.

The effect of root penetration has been previously noted in studies of south Westland soil sequences (Almond 1996) and it is considered to be an important contributing factor to the downward movement of tephra shards through root holes to below the horizon of initial deposition, particularly in soils with low accretion. The influence of younger carbon contamination has also been recognized in previous New Zealand studies by Grant-Taylor and Rafter (1971), Moar and Suggate (1979), and Hammond et al. (1991). These studies have demonstrated similar errors when peat and sediments are dated from the high rainfall, extreme leaching, and weathering environment of the west coast of the South Island. Through different acid/alkali pretreatments and by dating soluble (fulvic and humic acids) and insoluble fractions from bulk peat and sediment samples, these studies concluded that samples from loess, buried silt/sands, or peat older than $10 \mathrm{ka} \mathrm{BP}$ become significantly contaminated by younger carbon, particularly from humic and fulvic acids (Hammond et al. 1991).

To try to understand the nature and source of contamination in the bulk samples, 25 AMS age determinations were obtained from concentrated pollen, organic residue fractions, and macrofossils from a further 10 samples in the Okarito Pakihi core (Table 1). The pollen concentrates are defined as those that have a high pollen content, whereas the organic residue fractions contain a mix of organic matter or residue and pollen and are both sub-fractions of the sample $<125 \mu \mathrm{m}$. The fraction $<125$ $\mu \mathrm{m}$ contains a mix of pollen and organic residue (Table 1), whereas the fraction $>125 \mu \mathrm{m}$ contains large organic material. 

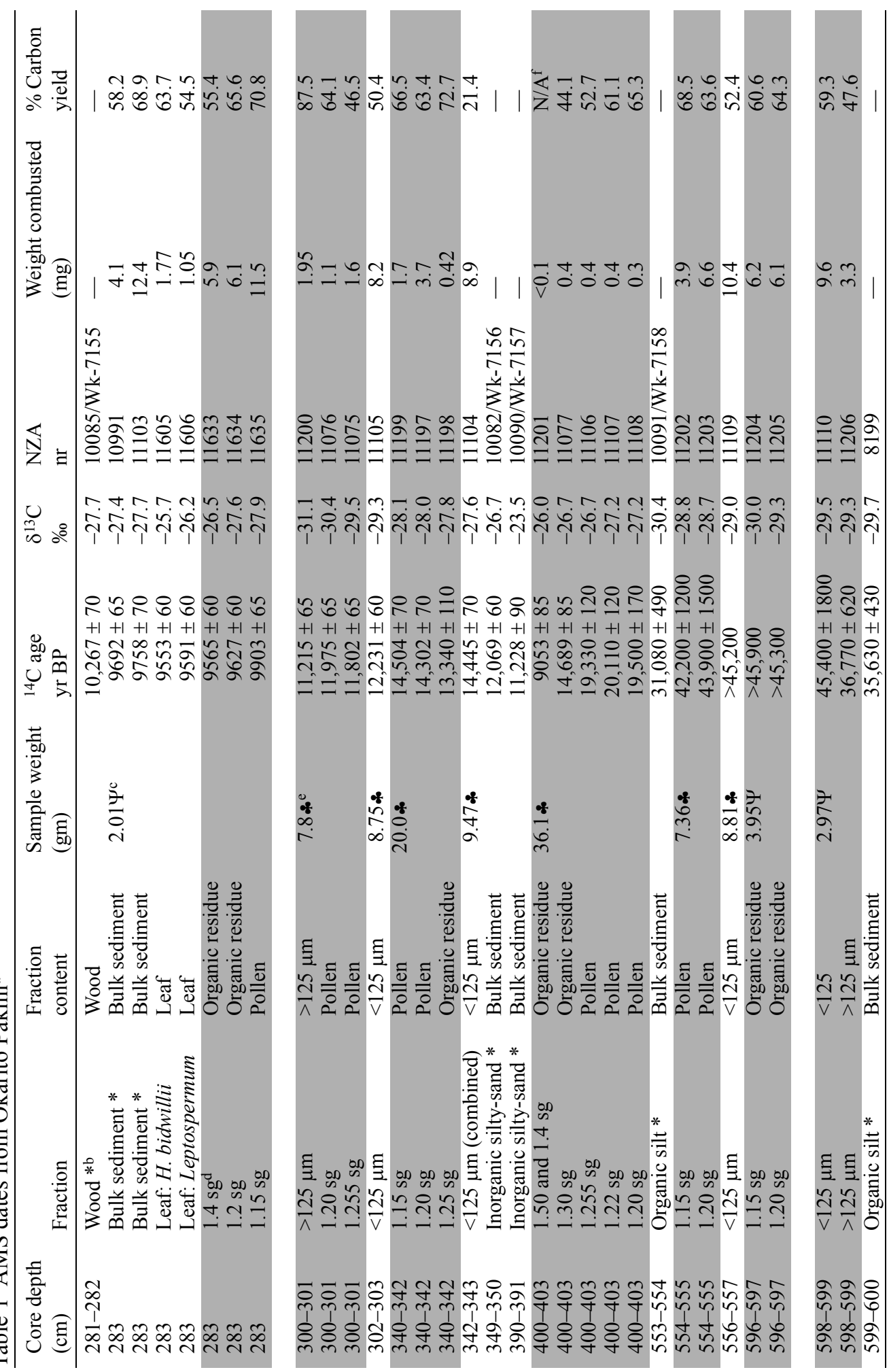

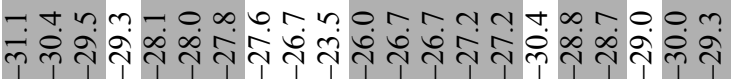

กิ่ กิ่

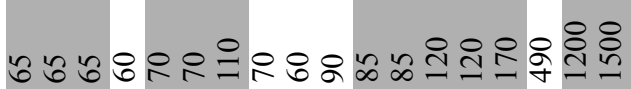

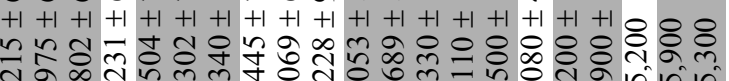

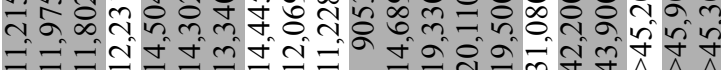

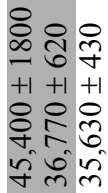

$\infty$
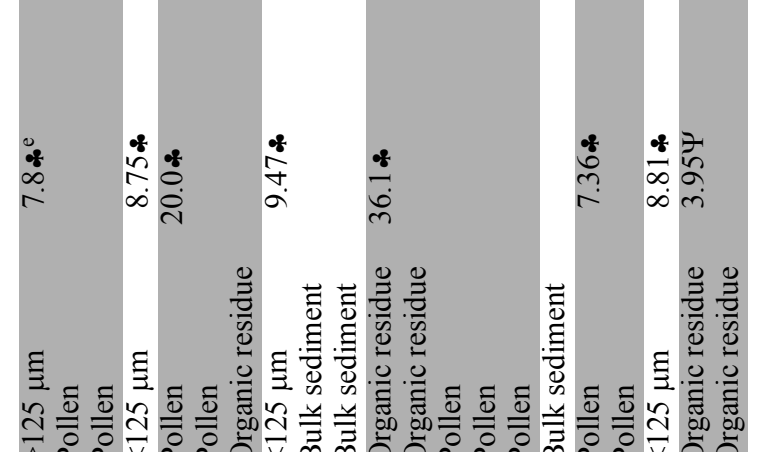

ヘ
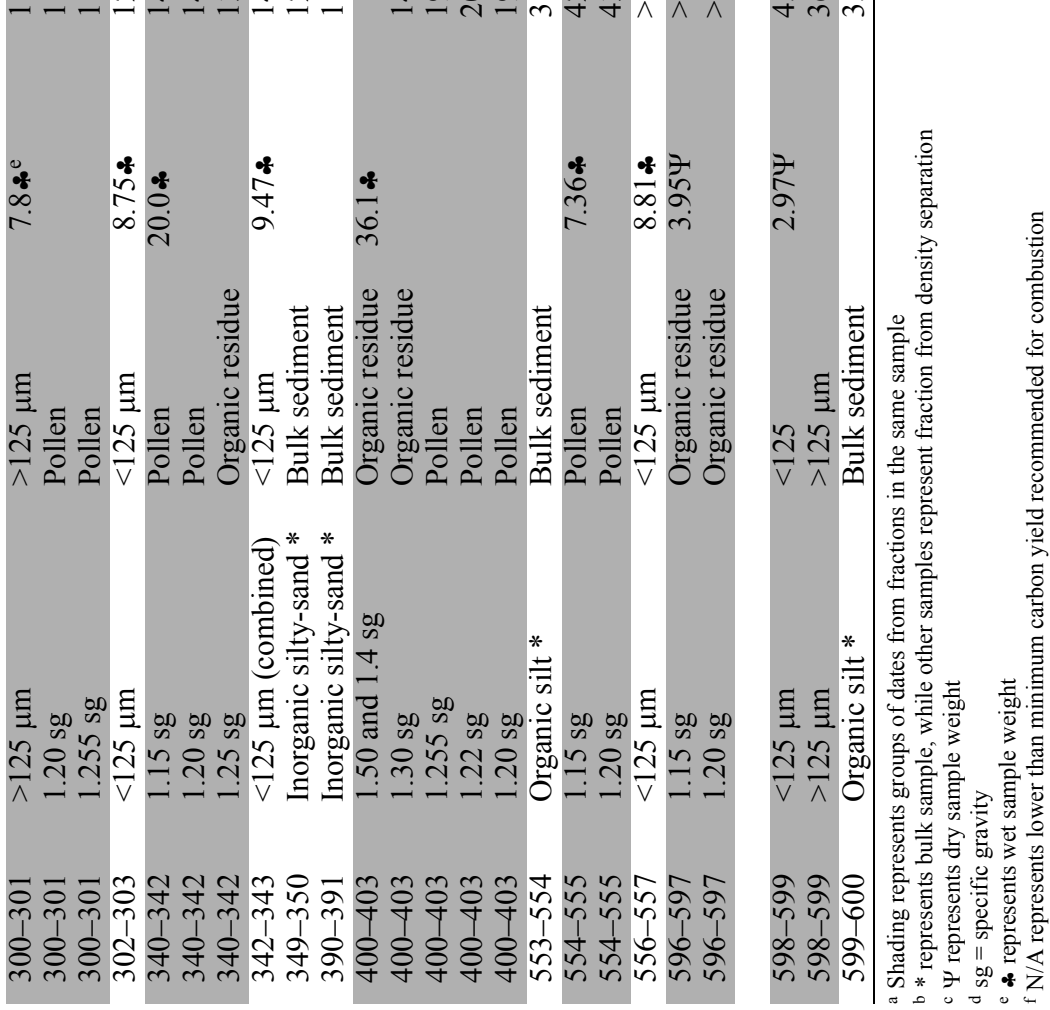


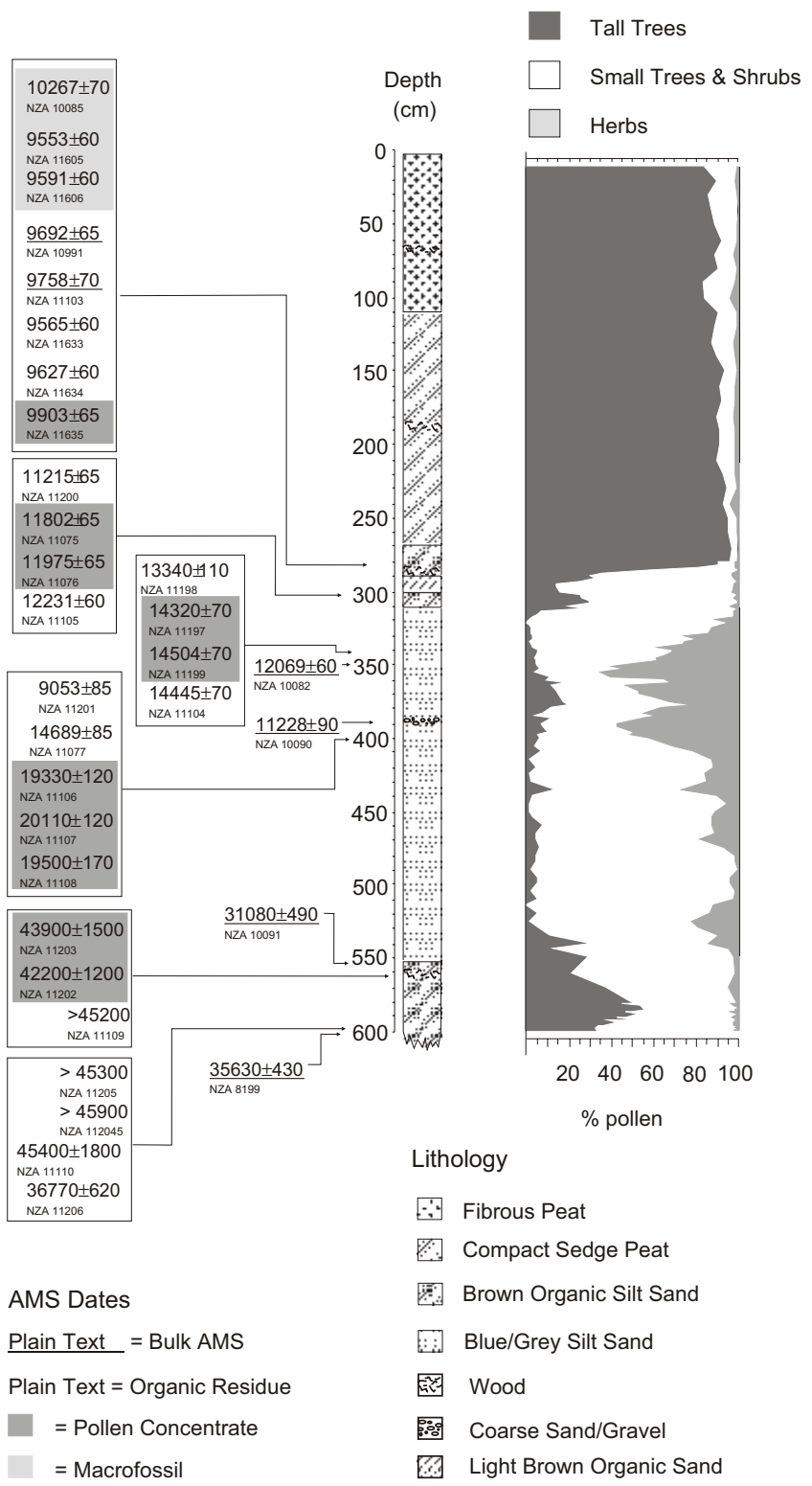

Figure 2 Summary diagram of Okarito Pakihi palynology showing location of dates in relation to major changes in pollen stratigraphy.

\section{POLLEN CONCENTRATE PREPARATION}

One-cm-thick samples were taken from sections in the core associated with major changes in the pollen stratigraphy (Figure 2). Between 310-500 cm, where the weight of the pollen fractions was too low for combustion, up to 2 additional samples were taken adjacent to each sample point and combined with the first sample prior to dating. Sample weights ranged between 2-3.95 g dry weight and 7.36-36.1 g wet weight (Table 1). 


\section{Chemical Treatment and Separation}

The method for pollen separation and concentration previously described by Prior and Chester (2001) is also outlined below and illustrated in Figure 3. Extraneous matter was removed according to standard methods (Faegri and Iversen 1989), including the removal of carbonates using $\mathrm{HCl}$, removal of humic acids using $\mathrm{KOH}$, and the removal of silica using HF. Dilute nitric acid was used to aid in the removal of organic residue. The mesh sizes of the sieves (125 and $6 \mu \mathrm{m})$ were selected to eliminate organic and inorganic matter both larger and smaller than most pollen (Figure 3). Sample separation by sieving is complemented by using Sodium Polytungstate (SPT) heavy liquid separation at a specific gravity ( $\mathrm{sg}$ ) of 2.1 , to separate most of the inorganic material from the lighter organic matter and pollen fraction. Between each step, samples were washed in distilled $\mathrm{H}_{2} \mathrm{O}$, centrifuged, and decanted to remove any remaining residue from the previous procedures. The samples were then processed for pollen separation prior to AMS dating. The procedure for pollen separation is summarized below.

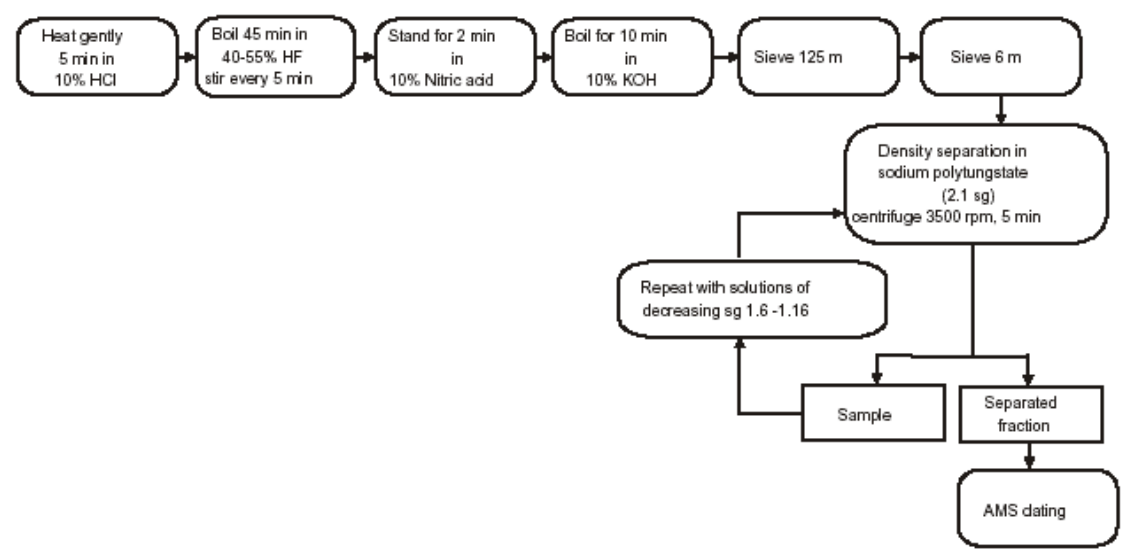

Figure 3 Summary flow chart of laboratory procedures used in preparation of pollen concentrates for AMS dating.

In each density separation cycle (Figure 3), SPT was thoroughly mixed with the sample, then centrifuged at $3500 \mathrm{rpm}$ for $5 \mathrm{~min}$. The supernatant was decanted and precipitates from each separation were saved as individual fractions and labelled with the density of the SPT used. For example, the pollen fraction dated at $283 \mathrm{~cm}$ precipitated at a specific gravity of $1.15 \mathrm{~g} \mathrm{~cm}^{-3}$ (Table 1). Sample material that floated in the supernatant was transferred to a clean centrifuge tube for the next separation. SPT was mixed to a specific gravity of $1.6 \mathrm{~g} \mathrm{~cm}^{-3}$ for the first separation and was decreased for each subsequent separation, repeating the cycle until all of the material in the sample had precipitated. For some samples, this was a density as low as $1.1 \mathrm{~g} \mathrm{~cm}^{-3}$. Microscope analysis of each separated fraction was undertaken to determine which fraction contained the highest concentration of pollen and the least concentration of organic residue. These pollen fractions were then preferentially selected for dating. Age estimates were also derived from fractions $>125 \mu \mathrm{m}$ and organic residue fractions separated by SPT. This was carried out in an attempt to identify which fractions were predominantly influenced by carbon contamination and to determine whether ages from combined fractions $<125 \mu \mathrm{m}$ provided considerably different ages to those obtained from the pollen fractions within the sample. 


\section{RESULTS AND DISCUSSION}

\section{Density Separation}

Pollen analysis carried out on each sample (to identify types and calculate percent pollen composition) indicates that pollen of dryland taxa and spores of the aquatic plant Isoetes dominated the pollen concentrates. This analysis showed no evidence of redeposited or ancient pollen within the dated samples and it is therefore unlikely that they are influenced by older carbon from this source. The sieved fractions $>125 \mu \mathrm{m}$ composed predominantly plant fragments and large organic residue and did not contain any recognizable pollen. The sieved fraction $<125 \mu \mathrm{m}$ contained a mix of pollen and finer organic residue. Density separation was carried out between 1.6 and $1.1 \mathrm{sg}$ on the $<125 \mu \mathrm{m}$ samples and Figure $4 \mathrm{a}-\mathrm{f}$ shows some of the typical results of the density separated fractions. Fractions separated at $>1.3 \mathrm{sg}$ contained predominantly organic residue and few pollen grains. The 1.3-1.15 sg fractions contained most of the separated pollen at varying concentrations between about $30-92 \%$. These fractions always contained some component of organic residue. The separated fractions $<1.15$ sg contained some pollen, primarily small grains and fine organic residue. Most tree pollen and dryland shrub species were found to separate at 1.15 and $1.2 \mathrm{sg}$. The visual estimates of pollen content were supplemented by the percent carbon yield during combustion of the different fractions (Table 1). Percent carbon yields of $65-70 \%$ in fractions identified as pollen indicate a high sporopollenin content (Prior and Chester 2001).

The purest pollen concentrates were derived from inorganic sediments which inherently had less organic residue. However, these samples also provided the lowest weight of sample for combustion (Table 1). Pollen concentrates from organic rich samples contained more organic residue, but provided greater weight for combustion.

\section{Dating}

AMS age determinations on the Okarito Pakihi sediments, macrofossils, and microfossils are listed in Table 1 and calibrated ages are listed in Table 2 and displayed in Figure 5a-d. Six ages derived from bulk samples throughout the core ranged from about 9.6-35.6 ka BP and indicate age inversions in the sediment record.

The pollen concentrate age from the sample taken at $283 \mathrm{~cm}$ provides an older age estimate than those derived from the organic residue fractions, leaf macrofossils, or bulk sediments (Table 1). Although these conventional ages generally remain within 2 standard errors of each other, calibrated ages (Table 2) clearly show that the pollen concentrates provide older age estimates than the other fractions from the same depth at the 2 sigma range (Figure 5a). The results also indicate that the 2 organic residue samples separated at 1.2 and 1.4 sg provide similar age estimates to those derived from both bulk sediments and leaf macrofossils. In contrast, the age derived from wood taken above this sample between $281-282 \mathrm{~cm}$ provides an older age estimate than the other ages at $283 \mathrm{~cm}$. It is not immediately obvious why the wood sample should provide an older age estimate for this depth than the samples below, but this may be an occurrence of the "old wood" problem. As most trees are long-lived species, their inner growth rings may be several hundred yr older than the time of death and deposition. Old-wood cores of large trees may survive processes of decomposition longer than the outer rings. Due to such potential ${ }^{14} \mathrm{C}$ age offset between time of growth and the time of deposition, many researchers advise the selection of single-growth-yr sample materials (Bowman 1990).

At 300-301 cm, pollen concentrate ages provide older age estimates for the sample than the sieved organic residue $>125 \mu \mathrm{m}$ from that depth (Table 1). When calibrated (Table 2), the pollen concen- 

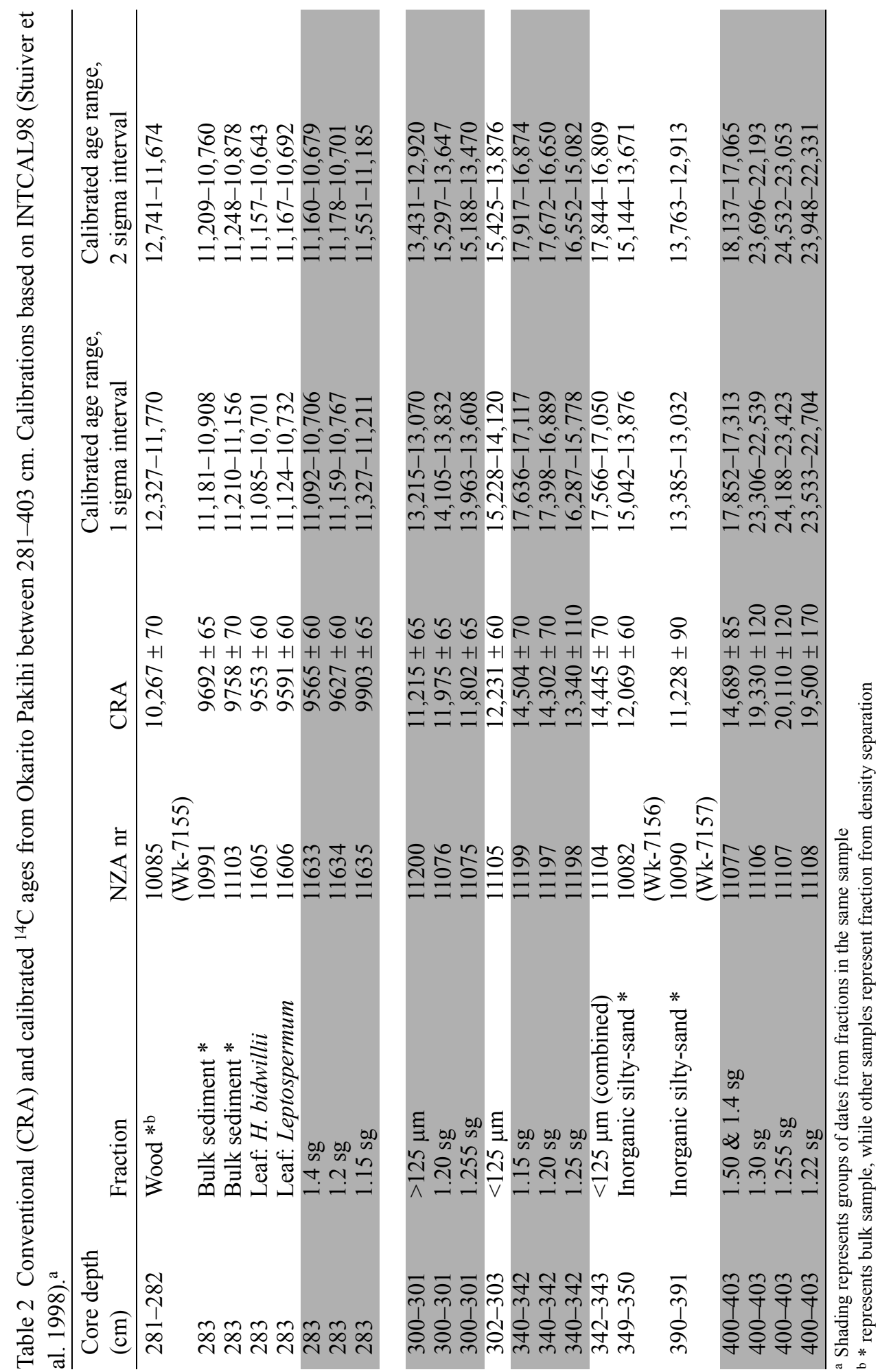


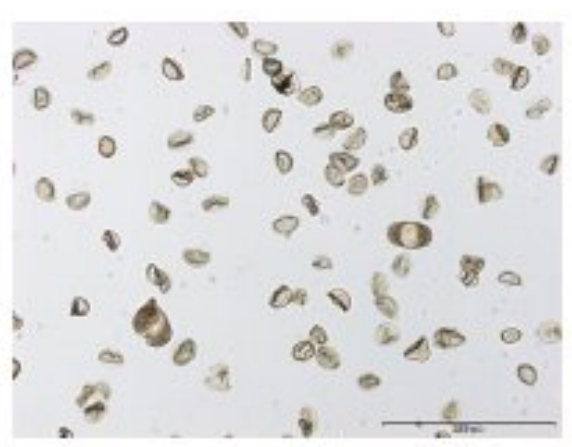

(A)

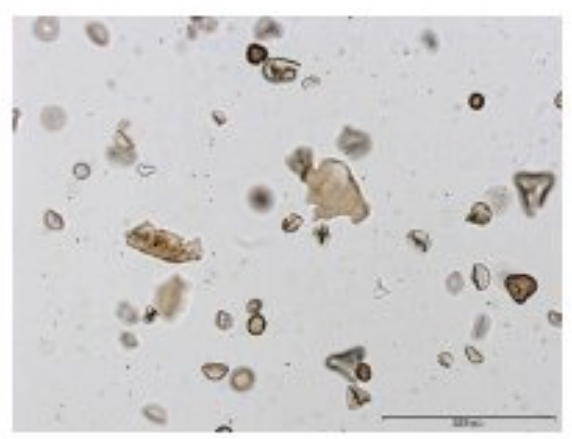

(C)

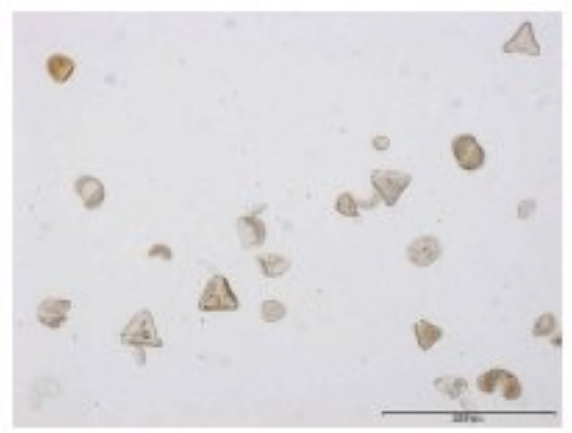

(E)

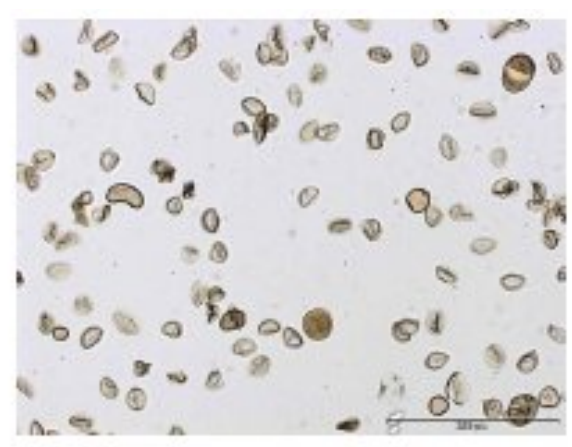

(B)

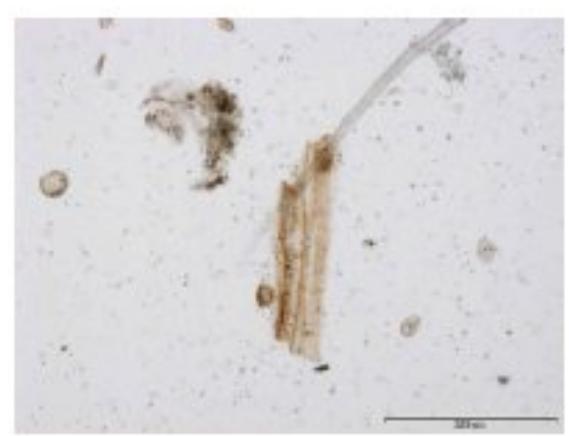

(D)

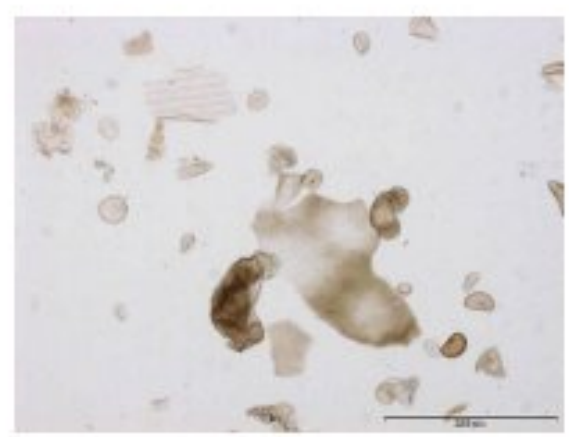

(F)

Figure 4 Examples of pollen concentrate and organic residue samples derived from density separation and AMS dated in this study. Pollen concentrates from $340-342 \mathrm{~cm}$ separated at $1.15 \mathrm{sg}$ (a) and $1.2 \mathrm{sg}$ (b) show little organic residue. Organic residue samples from 340-342 cm separated at $1.255 \mathrm{sg}$ (c) and $1.4 \mathrm{sg}$ (d): note increasing amounts of organic residue and lower pollen concentrations. The relative difference between a pollen concentrate (e) separated at $1.255 \mathrm{sg}$ and organic residue sample (f) separated at $1.30 \mathrm{sg}$ from $400-403 \mathrm{~cm}$ : note the greater presence of organic residue in $\mathrm{f}($ scale bar $=200 \mathrm{~mm})$. 

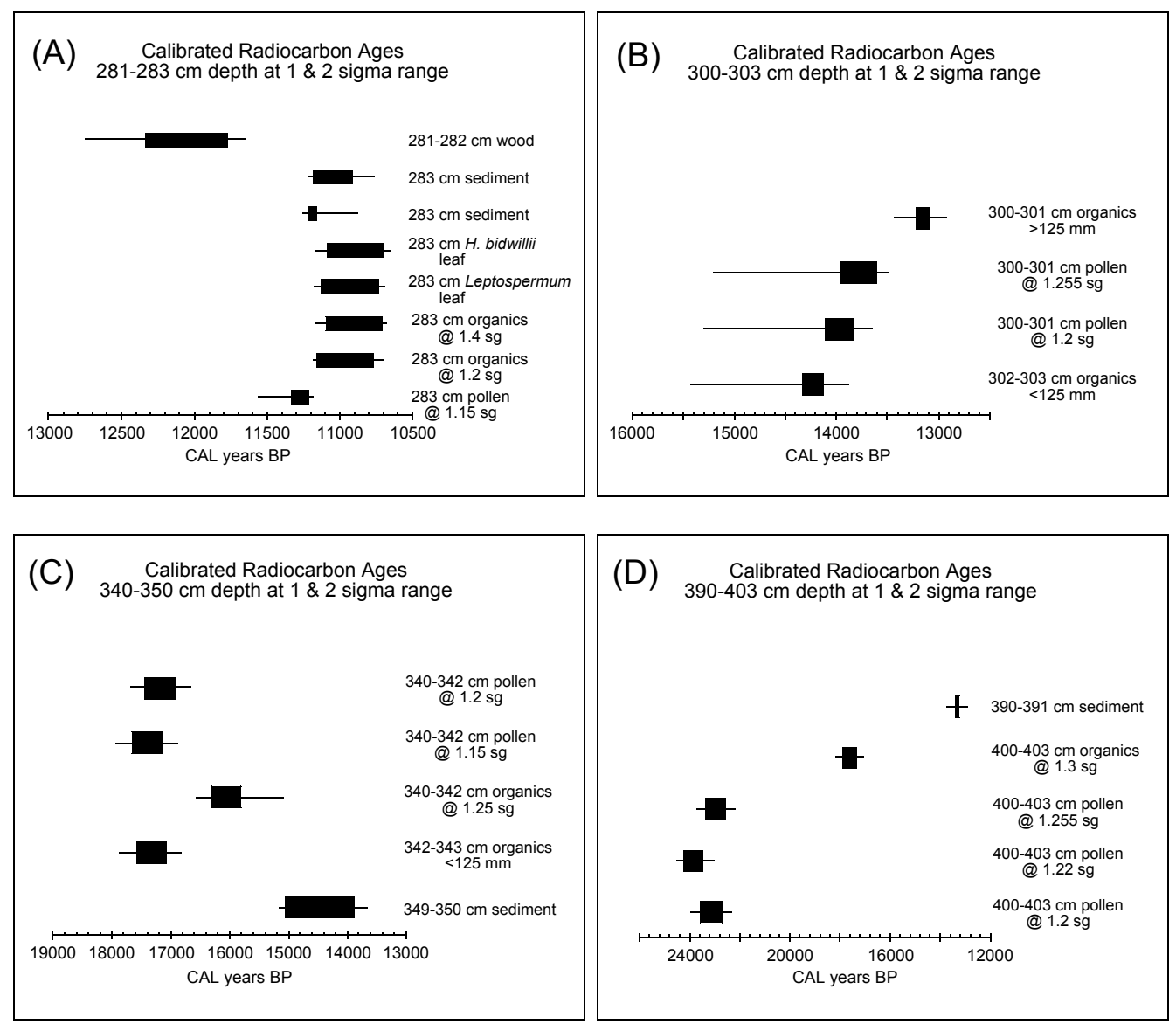

Figure 5 Comparison of calibrated ${ }^{14} \mathrm{C}$ ages between $281-283 \mathrm{~cm}$ (a), 300-303 cm (b), 340-350 cm (c), and 390-403 cm (d) from Okarito Pakihi. Plots show global calibrated age ranges at 1 and 2 sigma.

trate ages are comparable to a combined pollen and organic residue sample $<125 \mu \mathrm{m}$ taken from below this sample at 302-303 cm (Figure 5b). Pollen concentrate ages from the sediment between $340-342 \mathrm{~cm}$ provide older age estimates than the organic residue fraction from the same depth, and age estimates that are comparable to the combined pollen and organic residue sample $<125 \mu \mathrm{m}$ taken below this depth between $342-343 \mathrm{~cm}$ (Figure 5c). These ages also provide a convincingly older age estimate for this part of the sequence than the AMS age derived from a bulk sediment sample between 349-350 cm (Figures 2 and 5c). Ages from pollen concentrate and organic residue fractions between $400-403 \mathrm{~cm}$ also show marked differences, with the pollen concentrates providing age estimates that are approximately $4500 \mathrm{yr}$ older. However, the youngest organic residue age (NZA-11201) was combusted from an extremely small sample weight $(<0.1 \mathrm{mg})$ that did not produce a quantifiable percentage carbon yield (Table 1). Graphite produced from samples of less than $100 \mu \mathrm{g}$ is easily contaminated with modern carbon and we consider this age estimate completely unreliable. The pollen concentrate ages from between $400-403 \mathrm{~cm}$ also provide a significantly older age estimate for this part of the sequence than the AMS age derived from a bulk sediment sample between 390-391 cm (Figure 5d). Pollen concentrate ages from between 554-555 cm provide closely conforming age estimates that are considerably older than the age derived from a bulk sedi- 
ment sample between $553-554 \mathrm{~cm}$. These ages are considered to be close to the limit of ${ }^{14} \mathrm{C}$ dating as a combined pollen and organic residue sample $<125 \mu \mathrm{m}$ taken directly below this depth provides an infinite age estimate. Ages from organic residue fractions between $596-597 \mathrm{~cm}$ also provide infinite age estimates for this depth and are comparable to the combined pollen and organic residue sample $<125 \mu \mathrm{m}$ taken from between $598-599 \mathrm{~cm}$. The sieved organic residue $>125 \mu \mathrm{m}$ taken from the same sample between 598-599 cm provides a considerably younger and finite age estimate than the $<125 \mu \mathrm{m}$ fraction from this depth. This age, however, is comparable to the age estimate derived from the original bulk sediment sample from between 599-600 cm (Table 1).

\section{Sources of Error and Contamination}

A review of the AMS ages presented herein indicates that pollen concentrate ages provide consistently older age estimates for each sample than ages derived from organic residue or combined pollen and organic residue fractions in the respective sample. Furthermore, the age estimates from the pollen and organic residue samples below $550 \mathrm{~cm}$ indicate that the base of the sequence is beyond the limit of ${ }^{14} \mathrm{C}$ dating. It seems likely that the predominant source of error for the ages is in the organic residue and bulk organic fractions, and that at this particular site these fractions are prone to contamination by younger carbon. The most common form of contamination in high rainfall areas of New Zealand is by intrusion from younger plant material or humic acids (Hammond et al. 1991). It is likely that the younger age estimates reported here from the samples containing significant organic residues also results from the incorporation of younger plant material into the sample through root intrusion and possibly contamination from young humic acids percolating through the profile from the Holocene peat overlaying the deposit. The contaminating influence of humic acids has been previously noted (Head and Zhou 2000), where it was found to be incompletely removed from the sample by the standard acid/alkali/acid (AAA) pretreatment technique prior to dating. However, it is difficult to determine the specific contaminating agent from the results of this study.

The results from the ${ }^{14} \mathrm{C}$ dating confirm that the ages derived from pollen fractions are less likely to be influenced by carbon contamination than organic residue and bulk organic fractions. Consequently, it is likely that these ages provide a more reliable age for the vegetation changes in the sequence. When the pollen concentrate ages are compared to the bulk sediment AMS ages from Okarito Pakihi, the pollen fraction ages show that the bulk sediment ages provide spuriously young ages for the sequence and should therefore be regarded with caution (Figure 5).

\section{CONCLUSIONS}

The present study indicates that density separation of late Quaternary sediments using SPT is an effective method for concentrating pollen for AMS dating from relatively small sediment volumes and from sediments that contain relatively small pollen grains. However, it remains unsuccessful in completely removing all the organic residue and plant fibers from most samples. The dating of the pollen and organic fractions from Okarito Pakihi suggest that younger carbon is the main contaminant in late Quaternary peat and sediment samples. The likely source of contamination is the organic residue, which either constitutes or carries the younger carbon from either younger plant material or possibly undissolved humic acids. These findings suggest that at this site and others in the region, any sediment samples, but particularly those older than about $10 \mathrm{ka}$ BP that contain high concentrations of organic residue, may provide unreliable ages and should therefore be regarded with caution. The dating evidence indicates that the fractions containing high pollen ratios produced consistently 
older age estimates that are less likely to be influenced by contamination, and therefore, provide age estimates that are closer to the true age of the sample.

\section{FUTURE RESEARCH}

Although pollen fraction dating is used to overcome the dating inconsistencies in south Westland peat deposits older than about $10 \mathrm{ka} \mathrm{BP}$, further dating of these deposits with independent time markers is needed to determine the reliability of the pollen fraction ages. The recent identification of a distinctive tephra layer in loess profiles and peat deposits within close proximity of the site (Almond 1996; Almond et al. 2001; Vandergoes and Newnham, unpublished data) may provide a distinctive isochronous benchmark for testing the accuracy and reliability of this method.

\section{ACKNOWLEDGEMENTS}

The authors thank Dr Rewi Newnham, Dr Brent Alloway, and Dr James Crampton for helpful suggestions to improve the manuscript. We also thank Professsor Owen Davis and Tim Jull for reviewing the manuscript and Mark McClure for helpful editorial comments. This work was supported in part by the Institute of Geological and Nuclear Sciences Ltd PGSF programme Geological Time and Past Environments, contract number C05808. It also forms part of the $\mathrm{PhD}$ for Marcus Vandergoes, whose financial support for age determinations and materials was provided by the University of Otago Research Grants Committee.

\section{REFERENCES}

Almond PC. 1996. Loess, soil stratigraphy and the Aokautere Ash on late Pleistocene surfaces in south Westland: interpretation and correlation with the glacial stratigraphy. Quaternary International 32/33: 163-76.

Almond PC, Moar NT, Lian OB. 2001. Reinterpretation of the glacial chronology of south Westland, New Zealand. New Zealand Journal of Geology and Geophysics 44:1-15.

Bowman S. 1990. Radiocarbon Dating. London: British Museum Publications and Berkeley: University of California Press.

Brown TA, Nelson DE, Mathewes RW, Vogel JS, Southon JR. 1989. Radiocarbon dating of pollen by accelerator mass spectrometry. Quaternary Research 32: 205-12.

Brown TA, Farwell GW, Grootes PM, Schmidt FH. 1992. Radiocarbon AMS dating of pollen extracted from peat samples. Radiocarbon 34(3):550-6.

Chinn TJ, Whitehouse IE. 1980. Glacier snow line variations. Proceedings of the Riederalp Workshop, September 1978. International Association of Hydrological Sciences Publication 126:219-28. Wallingford: IAHS Press.

Faegri K, Iversen J. 1989. 4th edition. Textbook of Pollen Analysis. London: John Wiley \& Sons.

Garnier BJ. 1958. The Climate of New Zealand. London: Edward Arnold.

Grant-Taylor TL, Rafter TA. 1971. New Zealand radiocarbon age measurements-6. New Zealand Journal of Geology and Geophysics 14:364-402.
Hammond AP, Goh KM, Tonkin PJ, Manning MR. 1991. Chemical pretreatments for improving the radiocarbon dates of peats and organic silts in a gley podzol environment: Grahams Terrace, north Westland. New Zealand Journal of Geology and Geophysics 34:191-4.

Head MJ, Zhou WJ. 2000. Evaluation of $\mathrm{NaOH}$ leaching techniques to extract humic acids from palaeosols. Nuclear Instruments and Methods in Physics Research B 172:434-9.

Horrocks M, Deng Y, Nichol SL, Shane PA, Ogden J. 2002. A palaeoenvironmental record of natural and human change from the Auckland isthmus, New Zealand, during the late Holocene. Journal of the Royal Society of New Zealand 32:337-53

Long A, Davis OK, Delanois J. 1992. Separation and ${ }^{14} \mathrm{C}$ dating of pure pollen from lake sediments: nanofossil AMS dating. Radiocarbon 34(3):557-60.

Mensing SA, Southon JR. 1999. A simple method to separate pollen for AMS radiocarbon dating and its application to lacustrine and marine sediments. Radiocarbon 41(1):1-8.

Moar NT, Suggate RP. 1979. Contributions to the Quaternary history of the New Zealand flora. 8: interglacial and glacial vegetation in the Westport District, South Island. New Zealand Journal of Botany 17:361-87.

Moar NT, Suggate RP. 1996. Vegetation history from the Kaihinu (last) interglacial to the present, West Coast, South Island, New Zealand. Quaternary Science Reviews 15:521-47.

New Zealand Meteorological Service. 1983. Summaries of Climatological Observations to 1980. Miscella- 
neous Publication No. 177. Wellington: New Zealand Meteorological Service.

Prior CA, Chester PI. 2001. Precision radiocarbon dating of a late Holocene vegetation history. In: Jones M, Sheppard P, editors. Australasian Connections and New Directions: Proceedings of the 7th Australasian Archaeometry Conference. Auckland: University of Auckland. p 285-94.

Regnéll J. 1992. Preparing concentrates for AMS dating - a methodological study from a hard-water lake in southern Sweden. Boreas 21:373-7.

Regnéll J, Everitt E. 1996. Preparative centrifugation-a new method for preparing pollen concentrates suitable for radiocarbon dating by AMS. Vegetation History and Archaeobotany 5:201-5.

Richardson F, Hall VA. 1994. Pollen concentrate preparation from highly organic Holocene peat and lake deposits for AMS dating. Radiocarbon 36(3):407-12.

Stuiver M, Reimer PJ, Bard E, Beck JW, Burr GS, Hughen KA, Kromer B, McCormac FG, van der Plicht J, Spurk M. 1998. INTCAL98 radiocarbon age calibration, 24,000-0 cal BP. Radiocarbon 40(3):1041-83.

Warren G. 1967. Sheet 17 Hokitika Geological Map of New Zealand 1: 1:250 000. Wellington: New Zealand Geological Survey. 